\title{
Escala de Notas para Quantificação da Ferrugem em Eucalyptus*
}

\author{
Davi T. Junghans **, Acelino C. Alfenas \& Luiz A. Maffia \\ Departamento de Fitopatologia, Universidade Federal de Viçosa, CEP 36571-000, Viçosa, MG
}

(Aceito para publicação em 06/01/2003)

Autor para correspondência: Davi Theodoro Junghans

JUNGHANS, D.T., ALFENAS, A.C. \& MAFFIA, L.A. Escala de notas para quantificação da ferrugem em Eucalyptus. Fitopatologia Brasileira 28:184-188. 2003.

\section{RESUMO}

Utilizando tamanho de pústulas e número de soros como critérios para avaliar a severidade, estabeleceu-se a seguinte escala de notas para quantificação da ferrugem causada por Puccinia psidii em mudas inoculadas de Eucalyptus sp.: S0 = imunidade ou reação de hipersensibilidade, com necrose ou "fleck"; $\mathrm{S} 1$ = pústulas puntiformes, $<0,8 \mathrm{~mm}$ de diâmetro; $\mathrm{S} 2=$ pústulas medianas, de 0,8 a 1,6 mm de diâmetro; e S3 = pústulas grandes, > 1,6 mm de diâmetro. Aferiu-se essa escala mediante o uso do marcador RAPD AT9/917, geneti- camente ligado a um gene de resistência à ferrugem, em uma progênie de E. grandis. Apenas as plantas das classes S0 e S1 apresentaram o referido marcador e foram consideradas resistentes. A inconsistência na classificação de plantas resistentes e suscetíveis foi baixa (8\%). O uso dessa escala permitiu a seleção de grande número de plantas resistentes à ferrugem com relativa rapidez, facilidade e precisão.

Palavras-chave adicionais: severidade, avaliação da resistência, Puccinia psidii.

\section{ABSTRACT}

\section{Rating scale to eucalypts rust severity evaluation}

Based on the pustule size, a rating scale was developed for evaluation of rust severity in inoculated seedlings of Eucalyptus sp. as follow: $\mathrm{S} 0=$ immunity or hypersensitive reaction, with necrosis or fleck; $\mathrm{S} 1=$ small pustules, $<0.8 \mathrm{~mm}$ diameter; $\mathrm{S} 2=$ medium sized pustules, from 0.8 to $1.6 \mathrm{~mm}$ diameter and $\mathrm{S} 3=$ large pustules, $>1.6 \mathrm{~mm}$ diameter.
This scale was checked in a segregant progeny of E. grandis by using the RAPD AT9/917 marker, tightly linked to a rust resistance locus. Only plants classified as S0 and S1 had the RAPD marker and were considered resistant. The error in the classification of resistant and susceptible plants was low (8\%). The use of this scale allowed a very fast and accurate screening of rust resistant genotypes.
A ferrugem causada por Puccinia psidii Winter é uma das doenças mais severas na cultura do eucalipto (Eucalyptus sp.) no Brasil, com potencial de causar perdas em outras áreas tropicais e subtropicais do mundo que possuam florestas de eucalipto (Coutinho et al., 1998). O controle da doença pode ser feito por meio de fungicidas, colheita de árvores para aproveitamento da rebrota em época desfavorável à ferrugem e utilização de plantas resistentes, sendo esta última medida a mais indicada por seu menor custo, exeqüibilidade e menor impacto no ambiente (Alfenas et al., 1989).

A identificação de fontes de resistência à ferrugem em eucalipto tem sido feita a partir de infecções naturais, em áreas onde a enfermidade é severa ou, preferencialmente, mediante inoculação artificial, em condições controladas (Carvalho et al., 1998).

Para avaliação da resistência à ferrugem sob infecção natural, tem-se utilizado o índice de ferrugem, que considera a percentagem média de plantas doentes e o número médio de pústulas em 100 folhas de cada árvore (Dianese et al.,

\footnotetext{
* Parte da Tese de Doutorado do primeiro autor. Universidade Federal de Viçosa (2000).

**Bolsista do CNPq; Endereço atual: Embrapa Mandioca e Fruticultura, Cx. Postal 007, CEP 44380-000, Cruz das Almas, BA, e-mail: davi@cnpmf.embrapa.br Apoio Financeiro: FINEP/Fapemig/Suzano Bahia Sul
}

1984) ou o percentual de folhas (PFF) e ramos (PRF) com ferrugem (Ruiz et al., 1989c). Por outro lado, para avaliação de ferrugem em plantas inoculadas artificialmente, têm-se utilizado o número de soros totais (urediniais, teliais e mistos) em 2,4 cm² de área foliar (Ruiz et al., 1989a); os componentes de resistência, como período latente médio, freqüência de infecção, intensidade de infecção, produção de urediniosporos, período infeccioso e período latente (Castro, 1983; Coelho, 1988); e a distribuição e o tamanho de pústulas no limbo foliar (Ferreira \& Silva, 1982). As metodologias utilizadas na avaliação da resistência sob infecção natural têm considerado a variável incidência e não a severidade, como recomendado para ferrugens (Kranz, 1988). Em avaliações de campo, estas duas variáveis estão sujeitas a variações de ambiente e do patógeno, o que pode levar a conclusões conflitantes, como a classificação de um mesmo genótipo ora como medianamente suscetível, ora como resistente (Dianese et al., 1984; Dianese et al., 1986).

Dentre as metodologias para avaliar a resistência em plantas inoculadas artificialmente, a contagem do número de soros e a análise dos componentes de resistência apresentam as desvantagens de serem inviáveis quando se avaliam muitas amostras; necessitarem de equipamentos de microscopia e serem lentos para avaliação. Já a distribuição e o tamanho das pústulas são critérios exeqüíveis, mas as condições de 
ambiente e de inoculação descritas por Ferreira \& Silva (1982) são diferentes daquelas otimizadas para infecção da ferrugem do eucalipto (Ruiz et al., 1989a). Além disso, não há relação direta entre tamanho de pústulas e sua distribuição na folha. A distribuição de pústulas na folha relaciona-se com a distribuição de esporos do patógeno, enquanto o tamanho da pústula relaciona- se com a suscetibilidade do hospedeiro e com a agressividade do patógeno.

Não existe, portanto, uma metodologia padronizada e de fácil aplicação para avaliar a resistência à ferrugem em eucalipto. Diante da necessidade de analisar a severidade em grande número de plantas, desenvolveu-se uma escala de nota simples e precisa, em plantas artificialmente inoculadas, considerando a classe de severidade de acordo com o tamanho da pústula.

Clones, progênies de meios-irmãos e progênies de irmãos-completos de Eucalyptus grandis Hill ex Maiden foram inoculados com uma suspensão de urediniosporos de um isolado monopustular de $P$. psidii, UFV-2, obtido de $E$. grandis em Itapetininga, SP. Após a inoculação, as mudas foram mantidas em câmara de nevoeiro por $24 \mathrm{~h}$ no escuro, a $25{ }^{\circ} \mathrm{C}$, sendo posteriormente mantidas a $22^{\circ} \mathrm{C}$ com fotoperíodo de 12 h (Ruiz et al., 1989a) e intensidade luminosa de 40 $\mu$ moles fótons $/ \mathrm{m}^{2} / \mathrm{s}$.

Em inoculações prévias, notou-se uma resposta diferencial nas plantas inoculadas, expressa como classes distintas de tamanho das pústulas. Dessa forma, preconizouse uma escala com quatro graus de severidade: $\mathrm{S} 0=$ imunidade ou reação de hipersensibilidade, com necrose ou "fleck"; S1 = pústulas puntiformes; $\mathrm{S} 2$ = pústulas de tamanho mediano, com esporulação mais abundante que $\mathrm{S} 1$; e $\mathrm{S} 3$ = pústulas grandes e esporulação intensa em ambas as faces das folhas, podendo ocorrer em pecíolos e hastes jovens. Para definir os termos "puntiforme", "mediano" e "grande", avaliou-se, aos 12 dias após a inoculação (d.a.i.), o diâmetro de 40 pústulas e foi contado o número de soros urediniais em folhas representando cada classe de severidade, mediante o uso de uma escala métrica acoplada à ocular de uma lupa estereoscópica. A relação entre o valor da escala da ocular e o valor métrico real foi obtida pela determinação do fator de escala, para as magnificações de 25 e $50 \mathrm{X}$ usadas nessa mensuração.

Determinou-se a classe de severidade em indivíduos da progênie obtida do cruzamento entre os clones G38 (suscetível) e G21 (resistente). Para confirmação dessa avaliação, foram utilizados os marcadores AT9/917, AV10/765, AM6/ 440, AC8/1180, AE9/750 e K1/1130, derivados da região genômica que contém o gene de efeito principal na resistência. O marcador AT9/917 apresentou completa co-segregação com esse gene na progênie G38 x G21, ou seja, todas as plantas com este marcador foram resistentes e todas as sem ele foram suscetíveis (Junghans et al., 2000). A progênie de G38 x G21, composta por 1.000 plantas, foi dividida em quatro lotes para avaliação da severidade, feita sempre na terceira e quarta folhas apicais de cada muda inoculada. O primeiro lote, com 118 plantas, foi avaliado aos 12 e aos 24 d.a.i., e os três lotes restantes (com 312, 360 e 210 plantas) o foram aos 12 d.a.i.. A avaliação de severidade de cada planta foi realizada independentemente por dois avaliadores. Quando a classe de severidade de uma mesma planta diferia entre os avaliadores, uma avaliação conjunta era conduzida entre 16 e 18 d.a.i., obtendo-se um resultado comum. Definiram-se o tamanho médio das pústulas e o número médio de soros em plantas das classes S1, S2 e S3 de severidade, bem como seus limites superiores e inferiores (Tabela 1).

Considerando o diâmetro de cada pústula, definiu-se a seguinte escala de notas (Figura 1): $\mathrm{S} 0=$ imunidade ou reação de hipersensibilidade (HR), com necrose ou "fleck"; $\mathrm{S} 1$ = pústulas puntiformes, $<0,8 \mathrm{~mm}$ de diâmetro; $\mathrm{S} 2=$ pústulas medianas, de 0,8 a $1,6 \mathrm{~mm}$ de diâmetro; e $\mathrm{S} 3=$ pústulas grandes, $>1,6 \mathrm{~mm}$ de diâmetro, podendo ocorrer uredínias em pecíolos e hastes jovens.

Das 118 plantas do primeiro lote, avaliadas inicialmente aos 12 d.a.i., 59 foram resistentes (S0 ou S1). Duas das plantas classificadas como S1 não apresentaram o marcador molecular AT9/917, enquanto entre as 59 consideradas suscetíveis (S2 ou S3) três classificadas como S2 apresentaram o referido marcador (Figura 2).

Duas hipóteses podem justificar a avaliação errônea dessas cinco plantas: recombinação entre o gene de resistência e o marcador molecular ou erro na avaliação da resistência. Para dirimir essa dúvida, avaliou-se a presença dos outros cinco marcadores ligados ao gene de resistência (Junghans et al., 2000) em todas as 118 plantas desta progênie. Entre as 59 plantas resistentes ( $\mathrm{S} 0$ ou S1), 57 apresentaram todos ou a maioria dos outros cinco marcadores, e as duas plantas S1 que não apresentaram o marcador AT9/917, também não o fizeram com relação aos demais marcadores. Entre as 59 plantas suscetíveis, 56 não apresentaram a maioria dos cinco marcadores, enquanto que as três plantas S2 que apresentaram o marcador AT9/917, também exibiram os demais marcadores ligados à resistência à ferrugem.

Como não foram encontradas plantas da classe S0

TABELA 1 - Diâmetro de pústulas e número de soros urediniais nas classes S1 a S3 de severidade da ferrugem do eucalipto (Eucalyptus spp.)

\begin{tabular}{cccccccc}
\hline \hline \multirow{2}{*}{ Classe } & \multicolumn{2}{c}{ Diâmetro das Pústulas $(\mathbf{m m})$} & & & & \multicolumn{2}{c}{ Número de Soros Urediniais } \\
\cline { 2 - 4 } & Médio & Mínimo & Máximo & & Médio & Mínimo & Máximo \\
\hline S1 & $0,527( \pm 0,19)$ & 0,201 & 1,007 & & $1,78( \pm 0,85)$ & 1 & 4 \\
S2 & $1,223( \pm 0,37)$ & 0,806 & 1,813 & & $9,92( \pm 4,52)$ & 3 & 22 \\
S3 & $2,146( \pm 0,52)$ & 1,271 & 3,875 & & $28,19( \pm 7,74)$ & 16 & 42 \\
\hline
\end{tabular}




\section{D.T. Junghans et al.}

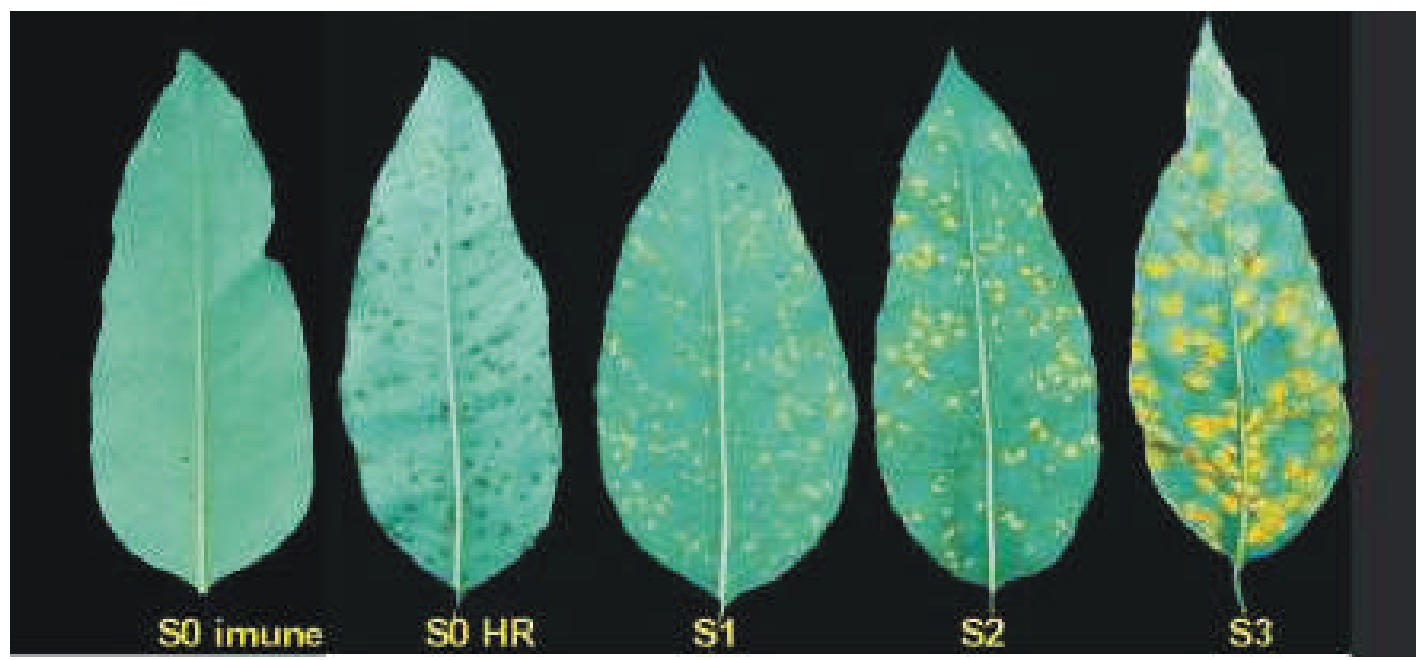

FIG. 1 - Escala de notas para avaliação da resistência à ferrugem do eucalipto (Eucalyptus sp.), com quatro classes de severidade: S0 = imunidade ou reação de hipersensibilidade do tipo "fleck" ou necrótico; $\mathrm{S} 1=$ pústulas $<0,8 \mathrm{~mm}$ de diâmetro; $\mathrm{S} 2=$ pústulas de 0,8 a 1,6 mm de diâmetro; e $\mathrm{S} 3$ = pústulas $>1,6 \mathrm{~mm}$ de diâmetro.

com ausência dos marcadores, nem plantas S3 com os marcadores moleculares derivados da região que contém o gene de resistência, concluiu-se que os erros no uso da escala de notas foram decorrentes da classificação errônea de algumas plantas nas classes S1 e S2, e não da recombinação genética.

$\mathrm{Na}$ avaliação das 118 plantas aos 24 d.a.i., classificaram-se 61 como resistentes e 57 como suscetíveis. Ao confrontar os dados desta segunda avaliação com a presença dos seis marcadores associados ao gene de resistência, constatou-se que apenas uma planta tinha sido avaliada erroneamente.

Comparando a avaliação das 118 plantas efetuada aos 12 e aos 24 d.a.i., observaram-se mudanças entre classes de severidade em uma mesma planta, com tendência de aumento na severidade da doença sem, contudo, alterar significa- tivamente a proporção de plantas resistentes e suscetíveis, com 59R:59S aos 12 d.a.i. e 61R:57S aos 24 d.a.i. (dados não mostrados). Em algumas plantas ocorreu redução da severidade, em razão do início de ressecamento de pústulas, com o desaparecimento da esporulação.

Entre as 882 plantas avaliadas nos lotes 2, 3 e 4, 210 diferiram na severidade entre dois avaliadores, 91 das quais foram classificadas como S1 por um avaliador e como S2 por outro, sendo avaliadas como resistentes por um avaliador e suscetíveis por outro. Dessas 91 plantas, 71 foram reavaliadas quanto à severidade aos 16-18 d.a.i. Confrontando as classes de severidade com a presença dos marcadores moleculares nessas 882 plantas, observou-se que 45 plantas $\mathrm{S} 1$ foram avaliadas erroneamente como S2 e 34 plantas S2 o foram como S1. Considerando as 1.000 plantas avaliadas e confrontando-se com a presença dos marcadores moleculares

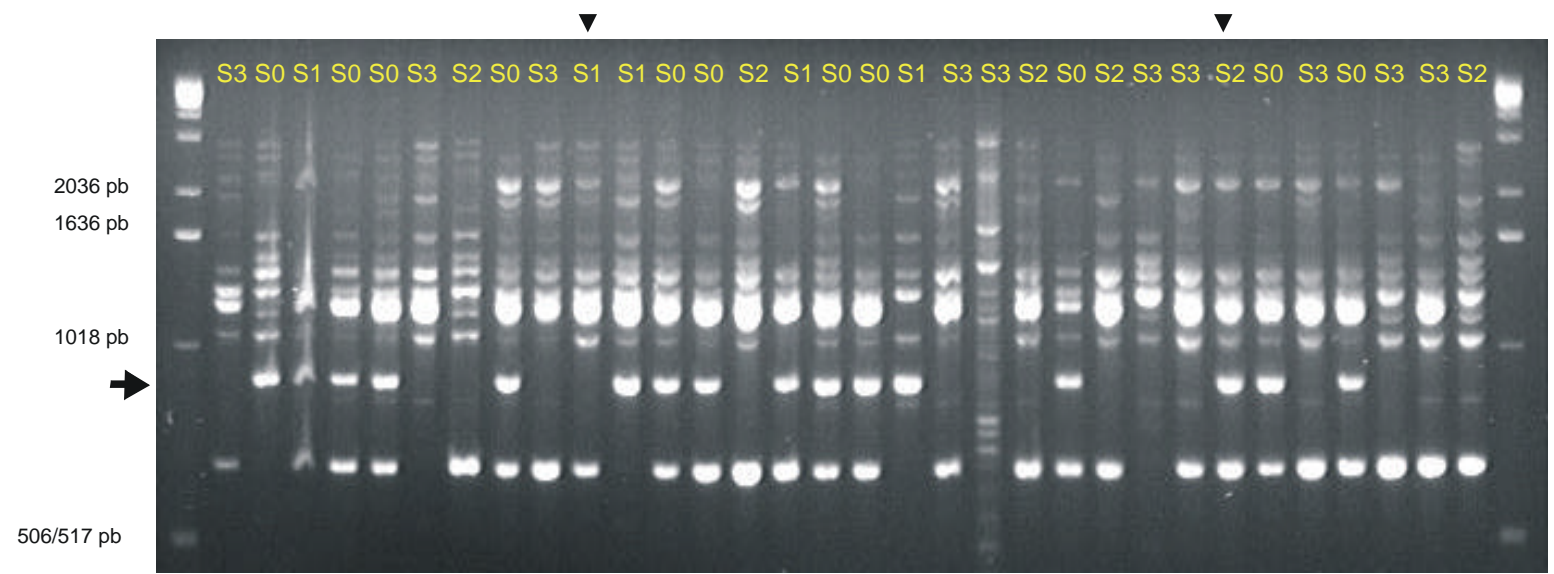

FIG 2 - Perfil eletroforético de DNA de indivíduos da progênie G38 x G21 amplificados com o primer AT9. A seta da esquerda indica a presença do marcador AT9/917 que co-segrega com a resistência à ferrugem do eucalipto (Eucalyptus sp.). As setas superiores mostram discrepâncias entre fenótipos resistentes (severidades S0 e S1) e ausência do marcador ou fenótipos suscetíveis (severidades S2 e S3) e presença do marcador. 
geneticamente ligados ao gene de resistência, a inconsistência no uso da escala de notas foi de $8 \%$.

A seleção de material resistente à ferrugem a partir de inoculações artificiais em mudas em condições controladas apresenta as seguintes vantagens em relação à infecção natural: a) a possibilidade de utilizar isolados do patógeno oriundos de diferentes regiões, b) o controle da idade, concentração e origem do inóculo, c) o controle do estádio de crescimento do hospedeiro e das folhas a serem avaliadas e d) a possibilidade de realizar avaliações em qualquer época do ano, independentemente de períodos favoráveis à doença. Particularmente, na ferrugem do eucalipto, isolados de $P$. psidii podem ser facilmente mantidos em mudas de jambeiro [Syzygium jambos (L.) Alston], com abundante produção de urediniosporos disponíveis para inoculação.

Com base no tamanho de pústulas, propôs-se uma escala de notas com quatro classes de severidade (S0, S1, S2 e S3) para avaliar a resistência à ferrugem em clones, procedências ou progênies de eucalipto. Neste trabalho, consideraram-se as classes S0 e S1 como resistentes e S2 e S3 como suscetíveis. Essa escala é aplicável em plantas inoculadas artificialmente, nas condições otimizadas por Ruiz et al. (1989a), e adota critérios simples e de fácil adaptação na seleção de materiais resistentes. Por se tratar de uma análise não-destrutiva, essa escala permite a avaliação dos materiais em datas sucessivas, conferindo maior acurácia na discriminação de materiais sob avaliação. Essa característica é, particularmente, útil na avaliação de materiais com período latente médio mais prolongado, uma vez que têm sido encontradas variações no período latente de 6,2 a 12,8 dias (Castro et al., 1985; Ruiz et al., 1989a). A utilização da escala de notas é sugerida na seleção de material resistente para fins científicos, para plantio comercial ou programas de melhoramento. A avaliação de um grande número de plantas, no presente trabalho, impossibilitou a determinação do período latente. No entanto, na avaliação da resistência à ferrugem em pequeno número de plantas, sugere-se que o período latente seja também determinado, adicionalmente à escala de severidade, em face à grande variação deste componente de resistência (Castro et al., 1983; Castro et al., 1985; Ruiz et al., 1989a).

$\mathrm{Na}$ escolha do método para quantificar uma doença, alguns fatores devem ser considerados, como tempo, praticabilidade, custo e acurácia. Comparada com o método de avaliação proposto por Ruiz et al. (1989a), a presente escala de notas permite avaliação mais rápida, por não depender de equipamentos de microscopia, e não incorre no erro de avaliar áreas preestabelecidas do limbo foliar, que pode resultar em imprecisões quando há distribuição irregular de pústulas na folha. Na presente escala de notas, diferentemente do método descrito por Ferreira \& Silva (1982), considera-se apenas o tamanho da pústula, desconsiderando sua distribuição na lâmina foliar. Neste caso, a resistência reflete a capacidade do hospedeiro de restringir o crescimento do patógeno no órgão inoculado, enquanto o número e a distribuição de pústulas, relaciona-se também com a distribuição de esporos do patógeno durante a inoculação.

A avaliação visual da severidade pode ser influenciada pela estrutura da planta e pelo tamanho e tipo da lesão. A escala aqui proposta não considera a estrutura da planta nem o tipo de lesão, pois avalia apenas a severidade na terceira e quarta folhas inoculadas, o que deve reduzir o percentual de erro associado ao uso de escalas de severidade. O treinamento de avaliadores, e não a escala de notas de doenças, aumenta a acurácia nas determinações visuais de severidade. Assim, sugere-se o treinamento prévio dos avaliadores anteriormente à avaliação da severidade da ferrugem do eucalipto.

Confrontando a classe de severidade com a presença ou ausência do marcador molecular AT9/917, ligado ao gene de resistência, verificou-se uma inconsistência de $8 \%$ na classificação entre plantas resistentes e suscetíveis, com tendência a superestimar a severidade, o que já foi observado em outras doenças (Kranz, 1988). Esse erro é similar ao encontrado na validação da escala desenvolvida para ferrugem do feijoeiro (Phaseolus vulgaris L.) (Godoy et al., 1997) e decorre da proximidade do limite de tamanhos superior e inferior das classes $\mathrm{S} 1$ e $\mathrm{S} 2$, respectivamente.

As estimativas de erro no uso de escalas de notas e escalas diagramáticas recaem sobre o avaliador e não sobre a escala per si. A validação da escala de notas proposta neste trabalho foi possível pela disponibilidade de marcadores moleculares ligados ao gene de resistência.

O ressecamento de pústulas constatado em algumas plantas entre 12 e 24 d.a.i. e a expressão tardia de sintomas de ferrugem podem induzir erros na avaliação de resistência em experimentos em condições controladas. Assim, sugerese que a avaliação da resistência à ferrugem em espécies, procedências, clones ou progênies de eucalipto seja conduzida em duas ou três datas, entre os 12 e 24 d.a.i., verificando para cada material genético avaliado a data de melhor expressão da resistência.

\section{REFERÊNCIAS BIBLIOGRÁFICAS}

ALFENAS, A.C., DEMUNER, N.L. \& BARBOSA, M.M. A ferrugem e as opções de controle. Correio Agrícola 1:18-20. 1989. CARVALHO, A.O., ALFENAS, A.C., MAFFIA, L.A. \& CARMO, M.G.F. Resistência de espécies, progênies e procedências de Eucalyptus à ferrugem, causada por Puccinia psidii Winter. Pesquisa Agropecuária Brasileira 33:139-147. 1998.

CASTRO, H.A. Padronização de metodologia de inoculação e avaliação da resistência de Eucalyptus spp. a ferrugem causada por Puccinia psidii Winter. ESALQ. (Tese de Doutorado). Piracicaba. ESALQ/USP. 1983.

CASTRO, H.A., KRUGNER, T.L. \& BERGAMIN FILHO, A. Especialização fisiológica no sistema Eucalyptus grandis - Puccinia psidii Winter. Ciência e Prática Lavras 9:80-92. 1985.

COELHO, L. Variabilidade fisiológica de Puccinia psidii Winter Ferrugem do eucalipto. (Tese de Mestrado). Viçosa. Universidade Federal de Viçosa. 1988.

COUTINHO, T.A., WINGFIELD, M.J., ALFENAS, A.C. \& CROUS, P.W. Eucalyptus rust: a disease with the potential for serious 


\section{D.T. Junghans et al.}

international implications. Plant Disease 82:819-925. 1998.

DIANESE, J.C., MORAES, T.S.A. \& SILVA, A.R. Response of Eucalyptus to field infection by Puccinia psidii. Plant Disease 68:314-316. 1984.

DIANESE, J.C., HARIDASAN, N. \& MORAES, T.S.A. Screening Eucalyptus for rust resistance in Bahia. Tropical Pest Management 32:292-295. 1986.

FERREIRA, F.A. \& SILVA, A.R.C. Comportamento de procedências de Eucalyptus grandis e de E. saligna à ferrugem (Puccinia psidii). Fitopatologia Brasileira 7:23-27. 1982.

GODOY, C.V., CARNEIRO, S.M.T.P.G., IAMAUTI, M.T., PRIA, M.D., AMORIM, L., BERGER, R.D. \& BERGAMIN FILHO, A. Diagrammatic scales for bean diseases: development and validation. Z. Pflkrankh. Pflschutz 104:336-345. 1997.

JUNGHANS, D.T., ALFENAS, A.C., BROMMONSCHENKEL,
S.H., ODA, S. \& MELLO, E.J. Fine genetic mapping of the rust (Puccinia psidii) resistance gene Ppr-1 in Eucalyptus grandis. Genetic and Molecular Biology 23:436. 2000 (Resumo).

KRANZ, J. Measuring Plant Disease. In: J. Kranz \& J. Rotem (Eds.) Experimental Techniques in Plant Disease Epidemiology. Heidelberg. Springer-Verlag. 1988. pp.35-50.

RUIZ, R.A.R, ALFENAS, A.C., FERREIRA, F.A. \& VALLE, F.X.R. Influência de temperatura, do tempo de molhamento foliar, fotoperíodo e da intensidade de luz sobre a infecção de Puccinia psidii em eucalipto. Fitopatologia Brasileira 14:55-61. 1989a.

RUIZ, R.A.R, ALFENAS, A.C. \& FERREIRA, F.A. Influência de temperatura, luz e origem do inóculo sobre a produção de urediniosporos e teliosporos de Puccinia psidii. Fitopatologia Brasileira 14:70-73. 1989b. 